\title{
Impact of Lipid Partitioning on the Design, Analysis, and Interpretation of Microsomal Time-Dependent Inactivation ${ }^{\mathbb{S}}$
}

\author{
Jaydeep Yadav, Ken Korzekwa, and Swati Nagar \\ Department of Pharmaceutical Sciences, Temple University School of Pharmacy, Philadelphia, Pennsylvania
}

Received December 18, 2018; accepted April 30, 2019

\begin{abstract}
Nonspecific drug partitioning into microsomal membranes must be considered for in vitro-in vivo correlations. This work evaluated the effect of including lipid partitioning in the analysis of complex TDI kinetics with numerical methods. The covariance between lipid partitioning and multiple inhibitor binding was evaluated. Simulations were performed to test the impact of lipid partitioning on the interpretation of TDI kinetics, and experimental TDI datasets for paroxetine (PAR) and itraconazole (ITZ) were modeled. For most kinetic schemes, modeling lipid partitioning results in statistically better fits. For MM-IL simulations $\left(K_{\mathrm{I}, \mathrm{u}}=0.1 \mu \mathrm{M}, \mathrm{k}_{\text {inact }}=0.1\right.$ minute $\left.^{-1}\right)$, concurrent modeling of lipid partitioning for an $\mathrm{f}_{\text {umic }}$ range $(0.01,0.1$, and 0.5$)$ resulted in better fits compared with post hoc correction (AICc: -526 vs. $-496,-579$ vs. -499 , and -636 vs. -579 ,
\end{abstract}

respectively). Similar results were obtained with Ell-IL. Lipid partitioning may be misinterpreted as double binding, leading to incorrect parameter estimates. For the MM-IL datasets, when $\mathrm{f}_{\text {umic }}=$ 0.02 , MM-IL, and Ell model fits were indistinguishable $(\delta \mathrm{AICc}=3)$. For less partitioned datasets ( $f_{\text {umic }}=0.1$ or 0.5 ), the inclusion of partitioning resulted in better models. The inclusion of lipid partitioning can lead to markedly different estimates of $\mathrm{K}_{\mathrm{l}, \mathrm{u}}$ and $\mathrm{k}_{\text {inact. }}$ A reasonable alternate experimental design is nondilution TDI assays, with post hoc $f_{\text {umic }}$ incorporation. The best fit models for PAR (MICM-IL) and ITZ (MIC-EII-M-IL and MIC-EII-M-Seq-IL) were consistent with their reported mechanism and kinetics. Overall, experimental $f_{\text {umic }}$ values should be concurrently incorporated into TDI models with complex kinetics, when dilution protocols are used.

\section{Introduction}

Mechanism-based inhibition results in time-dependent inactivation (TDI) of cytochrome P450 (P450) enzymes (Cohen et al., 1997; Mullins et al., 1998; Galetin et al., 2006; Obach et al., 2006; Venkatakrishnan and Obach, 2007; Watanabe et al., 2007; Zhou et al., 2007; Rowland Yeo et al., 2011). TDI is a major cause of drug-drug interactions (DDIs), and the potential for TDI is determined early in drug discovery using in vitro microsomal TDI assays. These assays provide two key parameters: $\mathrm{K}_{\mathrm{I}}$, the affinity of the inactivator, and $\mathrm{k}_{\text {inact }}$, the inactivation rate constant. The partitioning of drugs into microsomal membranes (nonspecific partitioning) decreases free drug concentration, which necessitates the measurement of fraction unbound in microsomes $\left(f_{u m i c}\right)$ (Margolis and Obach, 2003; Nagar and Korzekwa, 2012). $\mathrm{K}_{\mathrm{I}}$ values determined from microsomal TDI assays need to be corrected for

This work was supported by National Institutes of Health (NIH) [Grants R01GM114369 and R01GM104178]. This work is part of the Ph.D. dissertation thesis of J.Y. at Temple University.

https://doi.org/10.1124/dmd.118.085969.

S This article has supplemental material available at dmd.aspetjournals.org. binding/partitioning to obtain unbound parameters [e.g., unbound $\mathrm{K}_{\mathrm{I}}$ $\left(\mathrm{K}_{\mathrm{I}, \mathrm{u}}\right)$ ]. There are several studies reported in the literature demonstrating the importance of correction of microsomal binding and its effect on predicted pharmacokinetic parameters (Obach, 1997, 1999; McLure et al., 2000; Kalvass et al., 2001; Austin et al., 2002; Margolis and Obach, 2003; Nagar and Korzekwa, 2012; Waters et al., 2014). Drugs can range from very highly partitioned compounds [e.g., itraconazole (ITZ) and amiodarone] (Ishigam et al., 2001; Isoherranen et al., 2004; Galetin et al., 2005) to minimally partitioned compounds (e.g., diclofenac and ibuprofen) (Obach, 1999), depending on their physicochemical properties. Compounds with higher Log $\mathrm{P}$ values tend to highly partition into microsomes (Nagar and Korzekwa, 2012).

The most commonly used in vitro method is a two-step method to evaluate TDI (Grimm et al., 2009). This involves incubating the inactivator with microsomes in a primary incubation followed by a secondary incubation with another substrate to measure the remaining enzyme activity. This assay can be performed with either a dilution (to minimize competitive inhibition) or a nondilution design (Grimm et al., 2009). There has been considerable discussion regarding the advantages and disadvantages of the dilution versus nondilution methods (Parkinson et al., 2011; Mohutsky and Hall, 2014; Stresser et al., 2014). A characteristic

ABBREVIATIONS: 1-OH MDZ, 1-hydroxy midazolam; AICc, corrected Akaike information criterion; DDI, drug-drug interaction; DXO, dextrorphan tartrate; DXT, dextromethorphan hydrobromide; Ell, two binding site model; Ell-IL, two binding site model with lipid partitioning; $f_{u m i c}$, fraction unbound in microsomes; HLM, human liver microsome; I, inhibitor; IL, inactivator-lipid complex; ITZ, itraconazole; $\mathrm{K}_{\mathrm{l}}$, inhibitor binding constant; $\mathrm{K}_{\mathrm{l}, \mathrm{u}}$, unbound inhibitor binding constant; $\mathrm{k}_{\text {inact, }}$ inactivation rate constant; LC-MS/MS, liquid chromatography with tandem mass spectrometry; MDZ, midazolam; MIC, metabolite-intermediate complex; MIC-EII-IL, metabolite-intermediate complex with two molecules of inactivator binding simultaneously in the active site, and with inhibitor lipid partitioning; MIC-EII-M-IL, metabolite-intermediate complex with two molecules of inactivator binding simultaneously in the active site with metabolism of inhibitor; MIC-EII-M-Seq-IL, metabolite-intermediate complex with two molecules of inactivator binding simultaneously in the active site with metabolism of inhibitor with sequential metabolism of inhibitor; MIC-IL, metabolite-intermediate complex with inhibitor lipid partitioning; MIC-IL-M, metabolite-intermediate complex with inhibitor lipid partitioning with metabolism of inhibitor; MM, Michaelis-Menten kinetics; MM-IL, Michaelis-Menten kinetics with lipid partitioning; P450, cytochrome P450; PAR, paroxetine; PRA plots, plots of log percentage remaining activity versus preincubation time; Seq, sequential; TDI, time-dependent inactivation. 
of the dilution method is the use of a high concentration of microsomal protein (usually $>0.5 \mathrm{mg} / \mathrm{ml}$ ) in the preincubation phase. This can cause significant microsomal partitioning, decreasing free inactivator concentrations. DDI predictions can be significantly different, especially for compounds that are highly partitioned (e.g., amiodarone: $\mathrm{K}_{\mathrm{I}}=7.9 \mu \mathrm{M}$ vs. $\mathrm{K}_{\mathrm{I}, \mathrm{u}}=3.16 \mathrm{nM}$ ) (Rougee et al., 2017).

We have shown previously that using numerical methods to model TDI data has several advantages over the traditional replot method (Korzekwa et al., 2014; Nagar et al., 2014; Yadav et al., 2018): 1) Michaelis-Menten kinetics (MM) is not assumed and the frequently observed non-MM kinetics can be easily modeled; 2) parameter errors in all models (including MM) are significantly lower due to the lack of propagation of errors seen in the replot method; 3 ) other complexities such as quasi-irreversible inactivation, inhibitor loss, and sequential (Seq) metabolism can be modeled; and 4) the use of the numerical method has been shown to result in more accurate DDI predictions than the replot method. The replot method does have two advantages when MM kinetics applies. First, nonspecific enzyme loss is corrected by normalizing the dataset to the $[\mathrm{I}]=0$ controls. Second, residual competitive inhibition can be ignored since the replot of the data uses only the slopes of the remaining activity plots. As explained in the theoretical section, a dilution step shifts the partitioning equilibrium, resulting in higher free concentrations for highly partitioned compounds in the secondary incubation. This increased concentration of inactivator, and the resulting competitive inhibition, does not impact the estimation of $\mathrm{K}_{\mathrm{I}}$ for $\mathrm{MM}$ kinetics with the replot method, but must be considered with the numerical method.

We have previously shown that nonhyperbolic spacing in the slopes of PRA plots can be due to multiple binding [two binding site model (EII)] kinetics (Nagar et al., 2014) or the consumption of inactivator (Yadav et al., 2018). The Y-intercept of PRA plots displays the degree of competitive inhibition, which itself can be impacted by membrane partitioning. Since all data are modeled simultaneously with the numerical method, it is important to ascertain whether TDI parameters are impacted by covariance between the slope and the Y-intercept data.

In this work, simulations were used to investigate methods to include microsomal partitioning in vitro TDI models. Additionally, we evaluated the possible covariance between multisubstrate binding and lipid partitioning [i.e., can I $\rightarrow$ EI $\rightarrow$ EII be distinguished kinetically from $(\mathrm{I} \rightarrow \mathrm{EI})+(\mathrm{I} \rightarrow \mathrm{IL})$ ?]. Further, experimental in vitro TDI datasets were generated and analyzed for the CYP3A4 inactivator ITZ and the CYP2D6 inactivator paroxetine (PAR).

\section{Materials and Methods}

Solvents used for LC-MS/MS were obtained from Honeywell (B\&J AC/HPLC certified solvent) and were of analytical grade. PAR was obtained from Matrix Scientific (Columbia, SC). ITZ was obtained from Toronto Research Chemicals (North York, ON, Canada). Dextromethorphan hydrobromide (DXT) and dextrorphan tartrate (DXO) were purchased from Santa Cruz Biotechnology (Dallas, TX). N,N-Dimethylacetamide, midazolam (MDZ) and 1-hydroxy midazolam (1-OH MDZ) were obtained from SigmaAldrich (St. Louis, MO). Pooled ( $n=35$ livers) human liver microsomes (HLMs), NADPH solution A and solution B were obtained from Corning Life Sciences (Corning, NY).

\section{Theoretical Considerations}

Microsomal partitioning can be modeled in two ways with the numerical method, post hoc and concurrent. In the post hoc approach, total $\mathrm{K}_{\mathrm{I}}$ can be multiplied by the $\mathrm{f}_{\mathrm{umic}}$ to yield a $\mathrm{K}_{\mathrm{I}, \mathrm{u}}$. In the concurrent approach, microsomal binding can be modeled by adding a partitioning step (Fig. 1) to the kinetic scheme (similar to protein binding) where inactivator "I" forms a reversible complex with the lipid in the microsomes "L" forming IL.

In the traditional two-step in vitro TDI assay with dilution, aliquots of the preincubation mixture are added to the secondary incubation mixture containing NADPH and probe substrate. In the presence of microsomal partitioning, the dilution step causes a shift in the equilibrium of free and bound inactivator concentrations. The higher the microsomal partitioning, the greater is the shift in equilibrium toward higher than expected free inactivator concentrations in the secondary incubation (Fig. 1). Simulations with a dilution in vitro TDI assay at one inactivator concentration $(10 \mu \mathrm{M})$ are shown in Fig. 1. Fig. 1, A and B shows the free inactivator concentration with dynamic lipid partitioning for $\mathrm{f}_{\text {umic }}$ of 0.95 and 0.01 , respectively. It can be observed from Fig. 1A that minimal partitioning results in an equilibrium inactivator concentration similar to that expected upon dilution. In Fig. 1B, it can be seen that for compounds that partition highly into lipids, 1) at time 0 the free inactivator concentration is lower than the nominal concentration $(0.1$ vs. $10 \mu \mathrm{M})$, and 2) there is a significant shift in equilibrium during the dilution step, leading to a higher than expected inactivator concentration. Figure $1 \mathrm{C}$ shows the difference between the nominal (20-fold dilution) and actual fold dilution (dilution after re-equilibration, simulated across a range of $0-1 f_{\text {umic }}$ ). For example, for an inactivator with a $f_{\text {umic }}$ of 0.2 , the fold dilution will be only 5 -fold when the nominal fold dilution is 20 -fold. This will result in a free 4-fold higher inactivator concentration than expected in the secondary incubation. For potent inactivators like mibefradil, ritonavir, and ITZ, a higher inactivator concentration could violate the assumption of no inactivation in the secondary incubation.

A dilution step in a TDI assay is incorporated to minimize competitive inhibition in the secondary inhibition. In reality, high-affinity inactivators (relative to the substrate) can still cause competitive inhibition after dilution. Simulations using a 20 -fold dilution protocol were conducted with an MM dataset generated with minimal $(0.1 \%)$ error (Fig. 2). As shown in Fig. 2, the Y-intercept of a PRA plot shows the degree of competitive inhibition in the secondary incubation. Figure $2 \mathrm{~A}$ shows the PRA plot and replot for an inactivator with $K_{\mathrm{i}}=3 \mu \mathrm{M}$, and a substrate with $K_{\mathrm{m}}=1 \mu \mathrm{M}$. The $\mathrm{Y}$-intercept indicates minimal competitive inhibition in the secondary incubation. Figure 2B shows the PRA plot and replot for an inactivator with $K_{\mathrm{i}}=3 \mu \mathrm{M}$, and a substrate with $K_{\mathrm{m}}=30 \mu \mathrm{M}$. The Y-intercept indicates substantial competitive inhibition. In both cases, since only the slope of the PRA plot is used in the replot, any competitive inhibition (i.e., the difference is the Y-intercept) is ignored in the replot analysis, and identical TDI parameters are obtained. Thus, under the limiting conditions of MM kinetics, minimal experimental error (the replot method propagates errors), and the absence of any complicating factors (i.e., inhibitor loss, Seq metabolism, and quasi-irreversible intermediate formation), the traditional replot method is sufficient to estimate TDI parameters. Since these conditions are rarely met, the efforts in this manuscript are focused on defining the impact of microsomal partitioning on TDI parameter estimation using the numerical method.

\section{Methods}

Dataset Simulations and Model Fitting. To evaluate the impact of lipid partitioning on the estimation and interpretation of TDI kinetics, four models were evaluated: MM, MM-IL (i.e., MM with lipid partitioning), EII, and EII-IL (EII with lipid partitioning) (Fig. 3). Ordinary differential equations were constructed for all of the models, and simulated datasets were generated with two models (MM-IL and EII-IL), with a 20-fold dilution in the secondary incubation, and at the four different $f_{\text {umic }}$ values: $0.02,0.1,0.5$, and 0.9. Datasets were generated with a normally distributed $5 \%$ error. Fifty datasets were generated with both the MM-IL and EII-IL models. Simulations were performed for MM-IL with $\mathrm{K}_{\mathrm{I}, \mathrm{u}}=0.1 \mu \mathrm{M}\left(\mathrm{k}_{4}=270 \mu \mathrm{M} / \mathrm{min}\right.$ and $\mathrm{k}_{5}=27$ minutes $)$ and $\mathrm{k}_{\text {inact }}=$ 0.1 minutes. Simulations for EII-IL were performed with $\mathrm{k}_{4}=270 \mu \mathrm{M} / \mathrm{min}, \mathrm{k}_{5}=$ 27 minutes, $\mathrm{k}_{6}=0.02$ minutes, $\mathrm{k}_{7}=270 \mu \mathrm{M} / \mathrm{min}$, and $\mathrm{k}_{8}=0.25 \mu \mathrm{M} / \mathrm{min}$. To a first approximation, this results in a $\mathrm{K}_{\mathrm{I}, \mathrm{u} 1}=0.1 \mu \mathrm{M}, \mathrm{K}_{\mathrm{I}, \mathrm{u} 2}=1 \mu \mathrm{M}$, and $\mathrm{k}_{\text {inact }}=$ 0.14 minutes. For both the single- and double-binding models, $\mathrm{k}_{1}=270 \mu \mathrm{M} / \mathrm{min}$, $\mathrm{k}_{2}=1350$ minutes, and $\mathrm{k}_{3}=36$ minutes were used.

The initial inactivator concentrations $(n=8)$ used were between 0 and $80 \mu \mathrm{M}$ to appropriately bracket the $\mathrm{K}_{\mathrm{I}, \mathrm{u}}$ values (with a 2-fold dilution scheme), and 


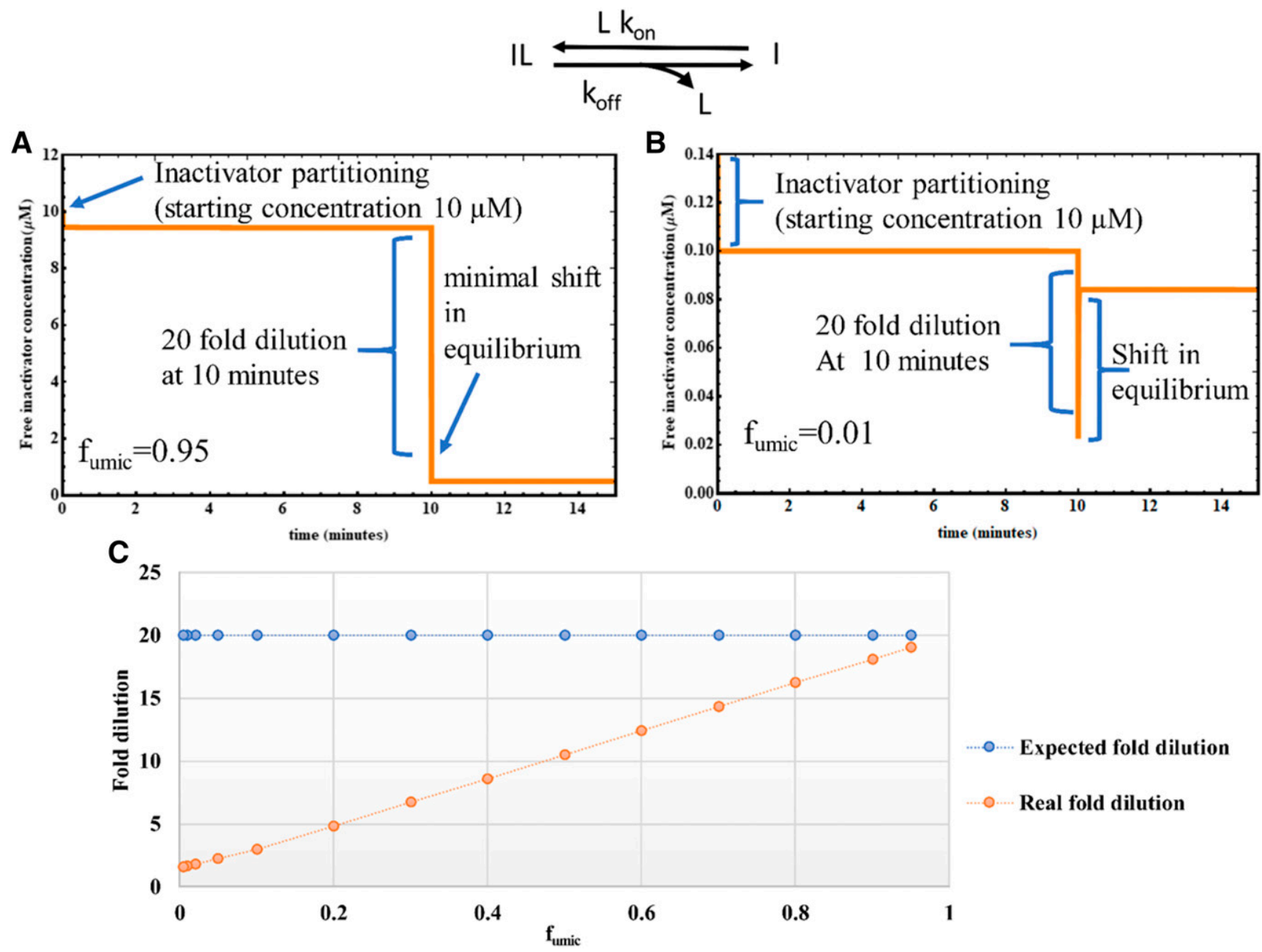

Fig. 1. Modeling the shift in equilibrium of inhibitor partitioning. An assay was simulated with $10 \mu \mathrm{M}$ inactivator concentration and 20 -fold dilution at 10 minutes. The orange curve in $(\mathrm{A}$ and $\mathrm{B})$ shows the change in free inactivator concentration with time. (A) Lipid partitioning modeled concurrently with $\mathrm{f}_{\text {umic }}=0.95$. $(\mathrm{B})$ Lipid partitioning modeled concurrently with $\mathrm{f}_{\text {umic }}=0.01$. (C) Difference in expected and observed fold dilution at different $\mathrm{f}_{\text {umic }}$. Nonsaturable partitioning is assumed (the change in lipid concentration with time $(\mathrm{dL} / \mathrm{dt})=0)$.

preincubation times were between 0 and 60 minutes with 10 time points for all datasets. The initial enzyme and substrate concentrations were set at 0.08 and $50 \mu \mathrm{M}$, respectively. All four models were individually fit to each simulated dataset.

For models incorporating nonspecific microsomal partitioning (MM-IL and EII-IL), lipid partitioning was modeled with $\mathrm{L} \cdot \mathrm{k}_{\mathrm{on}}=2000$ minutes, and $\mathrm{k}_{\text {off }}$ was calculated with eq. 1 at different $\mathrm{f}_{\text {umic }}$ values of $0.02,0.1$, and 0.5 :

$$
k_{\text {off }}=\frac{f_{\text {umic }} L k_{\text {on }}}{1-f_{\text {umic }}}
$$

where $\mathrm{L} \cdot \mathrm{k}_{\mathrm{on}}$ is a nominal lipid concentration (at $1 \mathrm{mg} / \mathrm{ml}$ microsomes) times the association rate constant, and $\mathrm{k}_{\text {off }}$ is the dissociation rate constant (see Fig. 1).
Simulations were also performed using a nondilution incubation method using MM-IL and EII-IL models at different $\mathrm{f}_{\text {umic }}$ values. While fitting incorrect models, initial estimates were varied to allow the model to converge. For example, while fitting an EII model to an MM-IL dataset, initial estimates for $\mathrm{k}_{5}$ and $\mathrm{k}_{7}$ were varied. AICc values were used for comparison of different models (Akaike, 1974), along with residual plots, correlation matrices, and parameter errors. All the simulated datasets were generated using the NDSolve function in Mathematica 11.1.1.0 (Wolfram Research, Champagne, IL).

The NonlinearModelFit function was used to fit models to the data with PrecisionGoal $=10$, finite difference derivatives with an order of 3 , and $1 / Y$ weighting. The WhenEvent function was used to simulate the dilution step in the secondary incubation. While fitting models to product concentrations, parameter estimates, parameter errors, and AICc values were stored for each
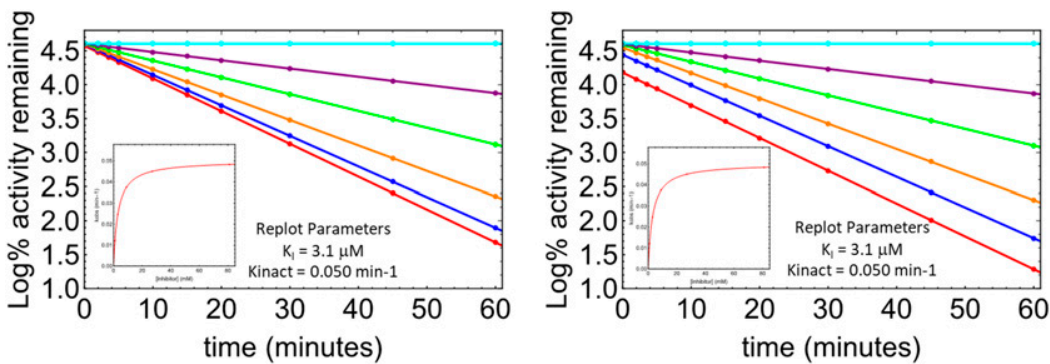

Fig. 2. Simulations of virtual TDI datasets with $0.1 \%$ error, with $\mathrm{MM}, \mathrm{K}_{\mathrm{I}}=3 \mu \mathrm{M}$, and $\mathrm{k}_{\text {inact }}=0.05$ minute. PRA plots are depicted, with inset replots. (Left) Substrate $K_{\mathrm{m}}=1 \mu \mathrm{M}$. (Right) Substrate $K_{\mathrm{m}}=30 \mu \mathrm{M}$. Competitive inhibition in the secondary incubation is observable in the Y-intercept of (Right). 
A

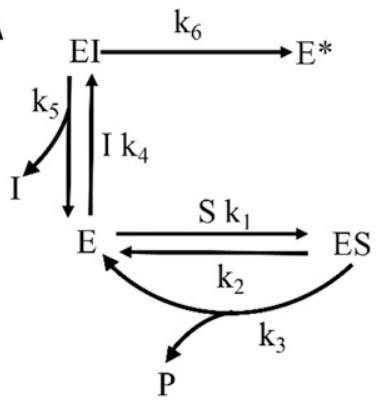

C

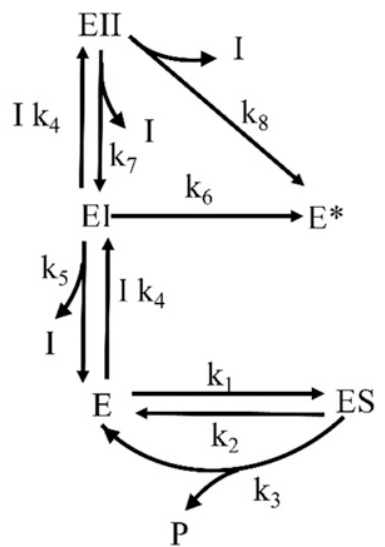

B

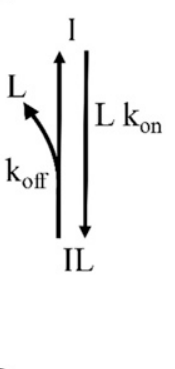

D

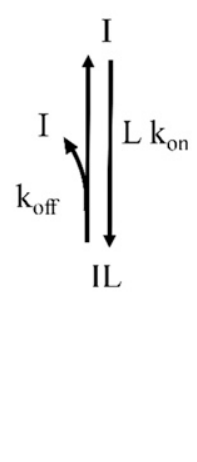

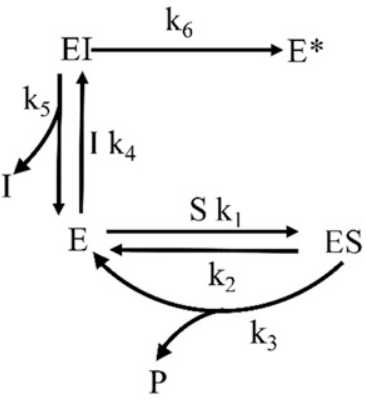
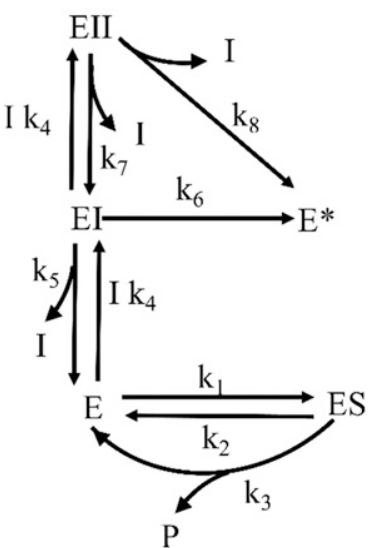

Fig. 3. Enzyme kinetic models used for simulating virtual TDI datasets with 5\% error. (A) MM model. (B) MM-IL model. (C) EII model. (D) EII-IL model. run. The average values of parameters and parameter errors were subsequently calculated for all runs.

Finally, although outside the immediate scope of this manuscript, it was observed that experimental $f_{u m i c}$ values are not always available, and simulations were performed to evaluate whether $f_{u m i c}$ can be predicted from in vitro TDI datasets. Also, previously generated experimental in vitro TDI datasets (Yadav et al., 2018) were used to estimate $f_{\text {umic }}$. The methods and results for this tangential exercise are included in the Supplemental Material.

Data Analysis. The datasets and the data generated from model fitting were stored for each run. Average values of parameters and parameter errors were calculated and reported. The $\mathrm{K}_{\mathrm{I}, \mathrm{u}}$ value was obtained directly from the models incorporating concurrent lipid partitioning as $\mathrm{k}_{5} / \mathrm{k}_{4}$ (using a rapid equilibrium assumption). For post hoc models, $\mathrm{K}_{\mathrm{I}, \mathrm{u}}$ was obtained by multiplying the total $\mathrm{K}_{\mathrm{I}}$ with $\mathrm{f}_{\text {umic }}$.

The resultant $\mathrm{k}_{\text {inact }}$ for double-binding models was calculated by using the net rate constant concept (Cleland, 1975). The equation used for calculating net $\mathrm{k}_{\text {inact }}$ for EIIs in Fig. 3, C and D was as follows:

$$
\mathrm{k}_{\text {inact }}=\frac{1}{\left(\frac{1}{\mathrm{k}_{4}^{\prime}}+\frac{1}{\mathrm{k}_{8}}+\frac{\mathrm{k}_{6}}{\mathrm{k}_{4}^{\prime}}\right)}+\frac{1}{\left(\frac{1}{\mathrm{k}_{6}}+\frac{\mathrm{k}_{4}^{\prime}}{\mathrm{k}_{6}}\right)}
$$

where $\mathrm{k}_{4}{ }^{\prime}$ is given by $\mathrm{k}_{4}^{\prime}=\frac{\mathrm{k}_{4} \mathrm{k}_{8}}{\mathrm{k}_{7}+\mathrm{k}_{8}}$

For multiple binding models, a ratio of $\mathrm{k}_{\mathrm{inact}} / \mathrm{K}_{\mathrm{I}, \mathrm{u} 1}$ was calculated using the net rate constant $\mathrm{k}_{\mathrm{inact}}$ and the first binding constant $\mathrm{K}_{\mathrm{I}, \mathrm{u} 1}$. When $\mathrm{K}_{\mathrm{I}, \mathrm{u} 1}$ is significantly smaller than $\mathrm{K}_{\mathrm{I}, \mathrm{u} 2}$, linear inactivation (at low [I]) is best described by the first binding event.

In Vitro TDI Incubations. Inactivators [ITZ as a CYP3A inhibitor (Mao et al., 2011) and PAR as a CYP2D6 inhibitor] were tested using a standard two-step approach for TDI inhibition of P450 enzymes using pooled HLM (Grimm et al., 2009; Yadav et al., 2018). MDZ was used as a probe substrate for CYP3A, and DXO was used as a probe substrate for CYP2D6. Briefly, eight concentrations of inactivators [ITZ $(0-5 \mu \mathrm{M})$ and PAR $(0-10 \mu \mathrm{M})$ ] were incubated at $37^{\circ} \mathrm{C}$ with a $1 \mathrm{mg} / \mathrm{ml}$ suspension of HLM in $0.1 \mathrm{M}$ potassium phosphate buffer, $\mathrm{pH} 7.4$, as a primary incubation. After 5 minutes of preincubation, the reaction was initiated by the addition of a NADPH regenerating system (final concentration, $1.3 \mathrm{mM} \mathrm{NADP}{ }^{+}, 3.3 \mathrm{mM}$ glucose- 6 phosphate, $0.4 \mathrm{U} / \mathrm{ml}$ glucose 6-phosphate dehydrogenase, and $3.3 \mathrm{mM}$ magnesium chloride). At specific time points, an aliquot $(7.5 \mu \mathrm{l})$ of the primary incubation was added to the secondary incubation $(142.5 \mu \mathrm{l})$ containing either $50 \mu \mathrm{M}$ MDZ or $75 \mu \mathrm{M}$ DXO, and NADPH. The primary incubation was run for 0-60 minutes, with data collected at a total of 13-14 time points. The secondary incubation was allowed to run for 2 minutes for CYP3A and 10 minutes for CYP2D6 followed by quenching with ice-cold acidified acetonitrile containing diltiazem as the internal standard. After centrifugation at $10,000 \mathrm{rpm}$ for 8 minutes, the supernatant was analyzed for either 1-OH MDZ or DXO. Stock solutions of PAR, MDZ, and DXT were prepared in methanol. The final methanol concentration in the primary incubation was less than $0.1 \%(\mathrm{v} / \mathrm{v})$. ITZ stock solutions were prepared in a mixture of $N, N$-dimethyl acetamide and acetone ( $12.5 \%$ and $87.5 \%$, respectively). The total final concentration of both the organic solvents was less than $0.1 \% \mathrm{v} / \mathrm{v}$. Incubations were also performed without inactivators to assess the nonspecific loss of enzyme activity. Both sets of incubations were performed in duplicate.

Microsomal Partitioning. Equilibrium dialysis was performed to determine microsomal partitioning of PAR in HLM, with a previously published method (Yadav et al., 2018). Briefly, a $0.5 \mathrm{mg} / \mathrm{ml}$ HLM suspension was spiked with PAR at a final concentration of $2 \mu \mathrm{M}$. A 96-well equilibrium dialyzer (Harvard Apparatus) was used to perform dialysis with a PAR-spiked HLM suspension on one side and blank phosphate buffer $(\mathrm{pH} 7.4)$ on the other side at $37^{\circ} \mathrm{C}$ for 20 hours. Samples on each side of the membrane were analyzed by LC-MS/MS for concentrations of PAR. For ITZ, four different values [0.056 at $0.25 \mathrm{mg} / \mathrm{ml}$ HLM (Galetin et al., 2005), 0.061 at $0.1 \mathrm{mg} / \mathrm{ml}$ HLM (Rougee et al., 2017), 0.051 at $0.2 \mathrm{mg} / \mathrm{ml} \mathrm{HLM} \mathrm{(Ishigam} \mathrm{et} \mathrm{al.,} \mathrm{2001),} \mathrm{and} 0.196$ at $0.025 \mathrm{mg} / \mathrm{ml}$ HLM (Isoherranen et al., 2004)] were obtained from the literature, and an average value of 0.0095 at a protein concentration at $1 \mathrm{mg} / \mathrm{ml}$ HLM was calculated using the method of Austin et al. (2002).

LC-MS/MS. Samples from in vitro TDI assays were analyzed with LC-MS/MS. Calibration curves were prepared in $0.05 \mathrm{mg} / \mathrm{ml}$ HLM in phosphate buffer (pH 7.4) spiked with analyte standards, followed by precipitation with acetonitrile. The supernatant was analyzed with LC-MS/MS. The LC system used was an Agilent 1100 series HPLC system. A Phenomenex Luna-C18 (3 $\mu \mathrm{m}, 30 \times$ $2 \mathrm{~mm})$ analytical column coupled with a C18 guard column $(4 \times 2.0 \mathrm{~mm})$ was used for chromatographic separation of $\mathrm{DXO}$ and 1-OH MDZ. Five microliters of sample volume was injected into the system. An AB Sciex API 4000 LC-MS/MS system was used for analyzing plasma samples in positive ion mode using the following MRM transitions: $342.092-324.100 \mathrm{~m} / \mathrm{z}$ for 
A

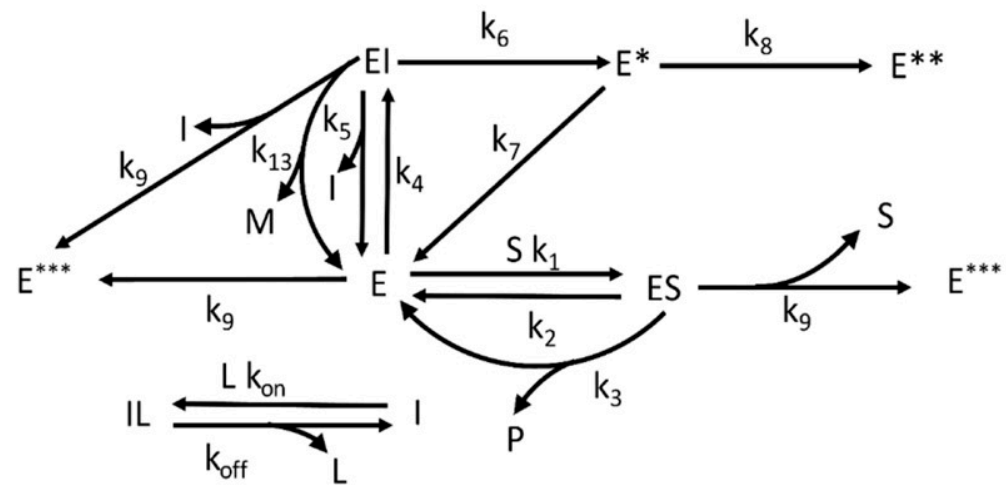

B

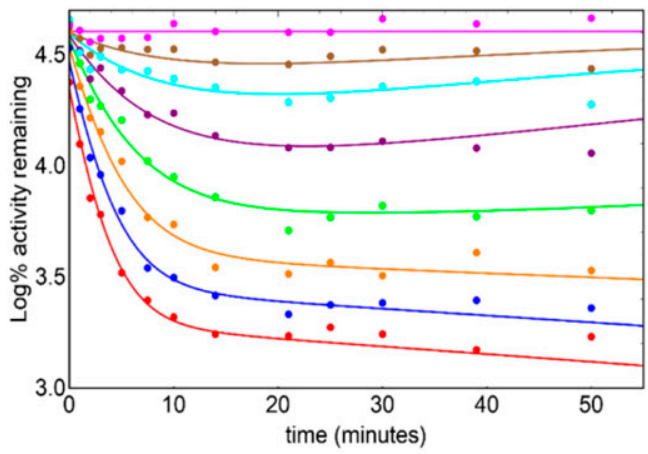

C

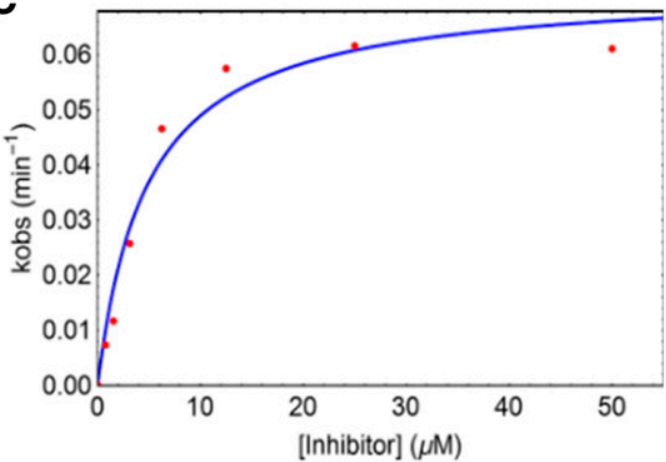

Fig. 4. Kinetic scheme for CYP2D6 inhibition by PAR (40, 20, 10, 5, 2.5, 1.25, 0.625, and $0 \mu \mathrm{M}$ ) in HLM. (A) Kinetic scheme for the MIC-M-IL model. (B) Experimental (points) and MIC-M-IL model fitted (solid lines) PRA plots. (C) Plot of $\mathrm{k}_{\mathrm{obs}} \mathrm{vs.}$ [ $[\mathrm{I}$ for the standard replot method with linear data points [ $n=4$ points in (B)]. E, enzyme; $\mathrm{k}$, rate constants; L, lipid; M, inhibitor metabolite; P, product; S, substrate. Nonspecific enzyme loss (E*** formation) was modeled from all active enzyme species as a first-order degradation. All parameter estimates are listed in Supplemental Materials.

1-OH MDZ; $258.113-199.200 \mathrm{~m} / \mathrm{z}$ for DXO; $331.27-70.257 \mathrm{~m} / \mathrm{z}$ for PAR; and $415.500-178.400 \mathrm{~m} / \mathrm{z}$ for diltiazem (IS). LC-MS solvents consisted of $0.1 \%$ formic acid in water as an aqueous mobile phase (A) and $0.1 \%$ formic acid in acetonitrile as organic mobile phase (B) for 1-OH MDZ and PAR, whereas $10 \mathrm{mM}$ ammonium acetate with $0.1 \%$ acetic acid was used as an aqueous mobile phase (A) and $0.1 \%$ formic acid in acetonitrile as organic mobile phase (B) for DXO. The flow rate was $0.7 \mathrm{ml} / \mathrm{min}$ for $1-\mathrm{OH} \mathrm{MDZ \text {, }}$ $0.55 \mathrm{ml} / \mathrm{min}$ for PAR, and $0.45 \mathrm{ml} / \mathrm{min}$ for DXO. The gradient elution used for $1-\mathrm{OH} \mathrm{MDZ}$ was programmed from $10 \%$ to $90 \% \mathrm{~B}$ in 0.5 minutes maintained at $90 \%$ until 1.1 minutes and returned to the initial condition at 2 minutes and maintained until 7 minutes. For DXO, the following gradient was used starting with $10 \% \mathrm{~B}$ and was maintained until 0.5 minutes, then to $95 \% \mathrm{~B}$ at 1 minute; and was maintained at $95 \%$ until 2.5 minutes, returned to initial conditions at 3 minutes, and was maintained until 7 minutes. The retention time for DXO was 2.8 minutes, and 4.25 for 1-OH MDZ. For PAR, the gradient elution used was programmed from $10 \%$ to $95 \%$ B in 1 minute, maintained at $95 \%$ until 2.5 minutes, returned to initial condition at 4 minutes, and was maintained until 8 minutes.

In Vitro TDI Model Development. Data obtained from in vitro TDI incubations were converted to a log percentage of the remaining activity plots (PRA plots) and were further evaluated for model development. Several enzyme kinetic models for P450 enzyme TDI were developed by incorporating MIC formation, inhibitor depletion, and concurrent lipid partitioning. A numerical method (Korzekwa et al., 2014; Nagar et al., 2014; Barnaba et al., 2016) was used to fit different models to the data. Initial estimates of rate constants were obtained using a previously published approach (Korzekwa et al., 2014; Nagar et al., 2014; Barnaba et al., 2016; Pham et al., 2017; Yadav et al., 2018). Briefly, $\mathrm{k}_{9}$ was incorporated into the models to account for nonspecific activity loss over time observed in the absence of inactivator ( $0 \mu \mathrm{M}$ inactivator), and the estimate was obtained by fitting a monoexponential loss model to $0 \mu \mathrm{M}$ inactivator data. Lipid partitioning was incorporated in the models to account for nonspecific partitioning to microsomes, as shown in Figs. 1, 4A, 5A, and 6A. I and L formed an I-L complex with an association rate constant at $2000 \mu \mathrm{M} / \mathrm{min}$. The dissociation rate constant was calculated using eq. 1. MIC formation was modeled as a multistep process (Barnaba et al., 2016) involving the formation of $\mathrm{Fe}^{+3}$ :carbene and $\mathrm{Fe}^{2+}$ :carbene. For example, in Fig. $5 \mathrm{~A}, \mathrm{k}_{6}$ and $\mathrm{k}_{12}$ form $\mathrm{Fe}^{+3}$ :carbene, $\mathrm{k}_{7}$ regenerates active enzyme, and $\mathrm{k}_{8}$ forms $\mathrm{Fe}^{2+}$ :carbene. $\mathrm{K}_{\mathrm{I}}$ values were estimated from ratios of association and dissociation rate constants (e.g., $\mathrm{k}_{5} / \mathrm{k}_{4}$ in Fig. 3). An $\mathrm{K}_{\mathrm{I}, \mathrm{u}}$ is obtained with the numerical method with concurrent modeling of lipid partitioning.

MIC-IL, MIC-IL-M (M refers to metabolism of inhibitor), MIC-EII-IL (two molecules of inactivator binding simultaneously in the active site), and MICEII-M-IL models were developed and evaluated. These models were tested separately for both inactivators. Additionally, an MIC-EII-M-Seq-IL model was tested for ITZ. In this model, the metabolite $\mathrm{M}$ is the inactivator, resulting in a lag time due to Seq metabolism. During model fitting, association rate constants were fixed at $270 \mu \mathrm{M} / \mathrm{min}$ (Barnaba et al., 2016) for PAR modeling. Since ITZ has a reported high affinity for CYP3A4, a $27 \mathrm{nM}$ (Isoherranen et al., 2004) sensitivity analysis was performed to optimize the association rate constant for ITZ. A value of $810 \mu \mathrm{M} / \mathrm{min}$ was used for the association rate constants for ITZ. This value is at the upper end of the typically observed range of $10^{7}-10^{4} \mathrm{M} / \mathrm{s}$, for small molecule-protein interactions (Fersht, 2017). For MDZ, the association and dissociation rate constants were fixed at $270 \mu \mathrm{M} / \mathrm{min}$ and 1350 minutes, respectively. For DXT, the association and dissociation rate constants were fixed at $270 \mu \mathrm{M} / \mathrm{min}$ and 2700 minutes, respectively. Parameter errors for net rate constants were calculated with error propagation for individual rate constants. AICc (Akaike, 1974), adjusted $R^{2}$, weighted residual plots, parameter errors, and correlation matrices were used to compare different models for each dataset.

\section{Results}

Simulated MM-IL datasets were generated with 5\% error at four different $\mathrm{f}_{\text {umic }}$ values $(0.02,0.1,0.5$, and 0.9$)$, as described in Methods. All four models (MM-IL, MM, EII, and EII-IL) were fit to each dataset, and results are shown in Table 1 . At $f_{\text {umic }}=0.02$, MM-IL and EII models had similar AICc values. However, estimates of $\mathrm{k}_{\mathrm{inact}}$ and $\mathrm{K}_{\mathrm{I}, \mathrm{u}}$ were different for the two models. The inactivation efficiency $\left(\mathrm{k}_{\text {inact }} / \mathrm{K}_{\mathrm{I}, \mathrm{u}}\right)$ was $3.47 \mu \mathrm{M} / \mathrm{min}$ for the EII model, whereas it was $1.00 \mu \mathrm{M} / \mathrm{min}$ for the MM-IL model. As the $\mathrm{f}_{\text {umic }}$ value approaches 
A

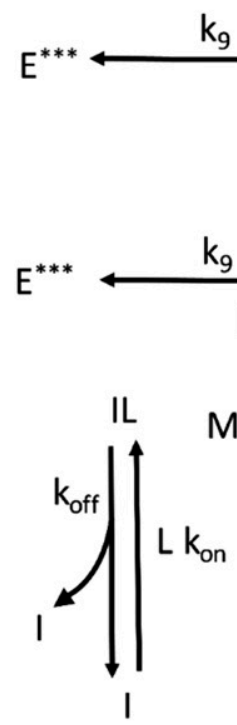

EII

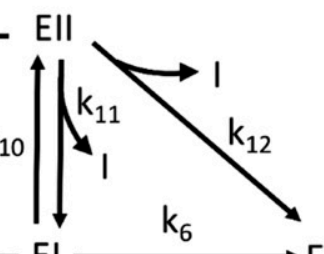

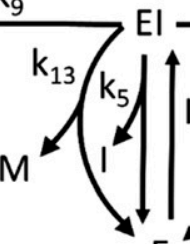

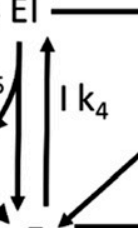

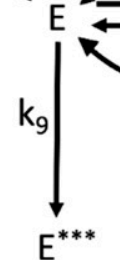

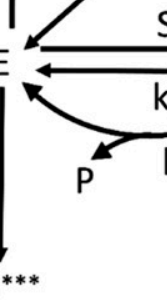

$\mathrm{Sk}_{1}$
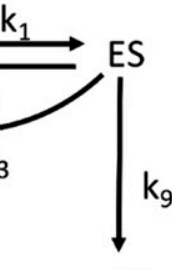

$\mathrm{E}^{* * *}$

B

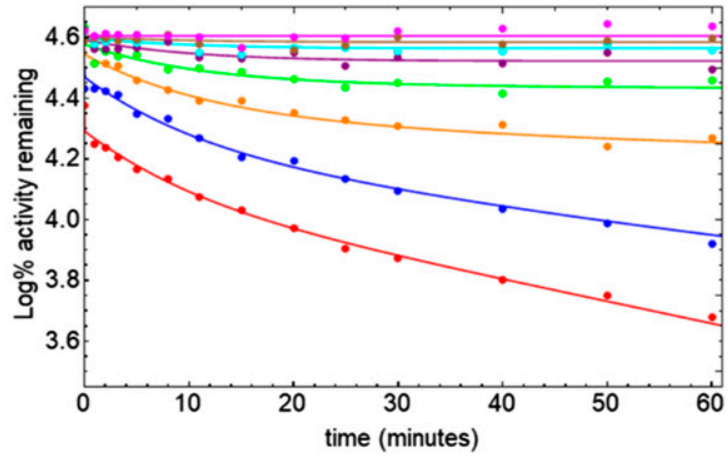

C

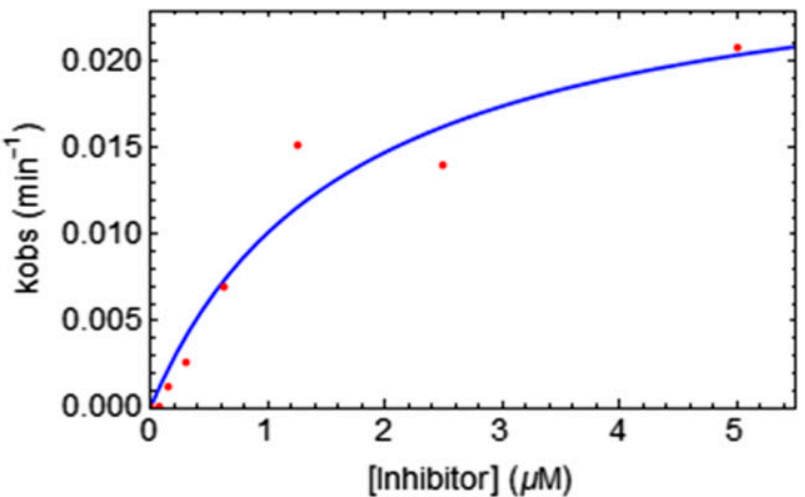

Fig. 5. Kinetic scheme (ITZ model 1) for CYP3A inhibition by ITZ $(5,2.5,1.25,0.625,0.3125,0.156,0.078$, and $0 \mu \mathrm{M}$ ) in HLM. (A) Kinetic scheme for MIC-EII-M-IL model. (B) Experimental (points) and MIC-EII-M-IL model fitted (solid lines) PRA plots. (C) Plot of $\mathrm{k}_{\mathrm{obs}}$ vs. [I] for the standard replot method with linear data points $[n=7$ points from (B)]. E, enzyme; I, inhibitor; $\mathrm{k}$, rate constants; $\mathrm{L}$, lipid; M, inhibitor metabolite; P, product; S, substrate. Nonspecific enzyme loss (E*** formation) was modeled from all active enzyme species as a first-order degradation. All parameter estimates are listed in Supplemental Materials.

1 (no partitioning), MM-IL collapses into MM, and EII-IL collapses into EII. Further, since MM models are nested in EII, the first binding and inactivation in EII $\left(\mathrm{K}_{\mathrm{I}, \mathrm{u} 1}\right.$ and $\left.\mathrm{k}_{\text {inact1 }}\right)$ is well defined and similar to MM. The second binding and inactivation in EII ( $\mathrm{K}_{\mathrm{I}, \mathrm{u} 2}$ and $\left.\mathrm{k}_{\text {inact } 2}\right)$ is not well defined, and these unnecessary parameters lead to increased AICc values. The convergence for the EII-IL model was less than $100 \%$ at all $\mathrm{f}_{\text {umic }}$ values.

Next, EII-IL datasets were generated with $5 \%$ error at four different $\mathrm{f}_{\text {umic }}$ values $(0.02,0.1,0.5$, and 0.9$)$. The results for model fitting to EII-IL datasets are shown in Table 2. At all $\mathrm{f}_{\text {umic }}$ values, EII-IL was always the best model (lowest AICc). As expected, as the $\mathrm{f}_{\text {umic }}$ value approached 1, both the EII and EII-IL models gave similar fits and became indistinguishable as EII-IL collapsed to EII.

At the lowest $\mathrm{f}_{\text {umic }}$ value (0.02), the MM and MM-IL models did not converge. The percentage of convergence of the MM and MM-IL models increased to $100 \%$ at $\mathrm{f}_{\text {umic }}=1$; however, $\mathrm{k}_{\text {inact }}$ and $\mathrm{K}_{\mathrm{I}}$ were both overpredicted. Also, EII and EII-IL could be identified as the better models.
Finally, simulations were performed with a nondilution incubation method using MM-IL and EII-IL with $\mathrm{f}_{\mathrm{umic}}=0.02\left(\mathrm{f}_{\mathrm{umic}}\right.$ values of 0.1 and 0.5 provided similar results; data not shown). It was observed that the estimated inactivation efficiency $\left(\mathrm{k}_{\text {inact }} / \mathrm{K}_{\mathrm{I}, \mathrm{u}}\right)$ was identical for both methods of lipid-partitioning corrections (concurrent and post hoc) at different $f_{\text {umic }}$ values (Table 3 ) in the absence of dilution of the secondary incubation.

Experimental In Vitro TDI. For PAR, various models that included concurrent lipid partitioning were tested. The following models were tested (AICc): MIC-IL (-718), MIC-M-IL (-762), MIC-EII-IL (-728), and MIC-EII-M-IL (-758). EII refers to double binding of I to E. The MIC-M-IL model (Fig. 4A) was found to be the best fit model. The MIC-M-IL model was able to capture the concave upward curvature in the dataset (Fig. 4B). Using the numerical method with concurrent $\mathrm{f}_{\mathrm{umic}}$ modeling, $\mathrm{K}_{\mathrm{I}, \mathrm{u}}$ and $\mathrm{k}_{\text {inact }}$ estimates of PAR were $0.61 \pm 0.09 \mu \mathrm{M}$ and $0.005 \pm 0.001$ minute, respectively (Table 4 ). Further, the $\mathrm{k}_{\text {inact }} / \mathrm{K}_{\mathrm{I}, \mathrm{u}}$ value of PAR was estimated to be $0.008 \pm 0.002 \mu \mathrm{M} / \mathrm{min}$ using the numerical method,
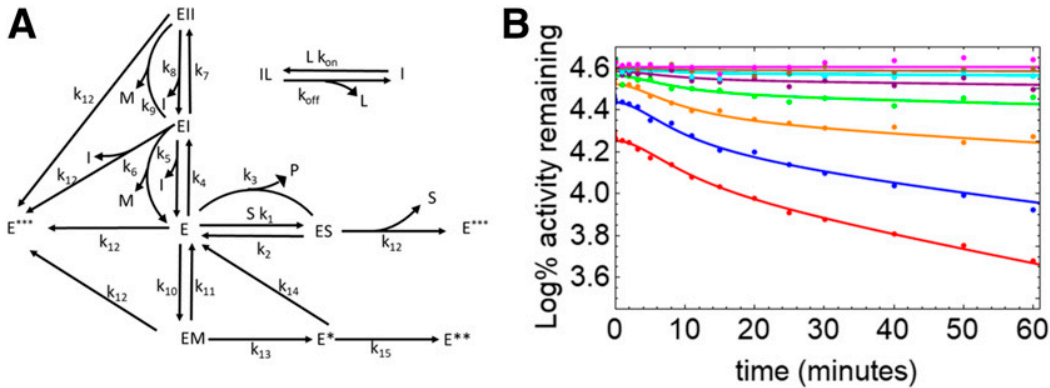

Fig. 6. Kinetic scheme (ITZ model 2) for CYP3A inhibition by ITZ $(5,2.5,1.25,0.625,0.3125,0.156,0.078$, and $0 \mu \mathrm{M})$ in HLMs. (A) Kinetic scheme for the MIC-EII-M-Seq-IL model. (B) Experimental (points) and MIC-EII-M-Seq-IL model fitted (solid lines) PRA plots. E, enzyme; I, inhibitor; k, rate constants; L, lipid; M, inhibitor metabolite; P, product; S, substrate. Nonspecific enzyme loss ( $\mathrm{E}^{* * *}$ formation) was modeled from all active enzyme species as a firstorder degradation. All parameter estimates are listed in Supplemental Materials. 
Yadav et al.

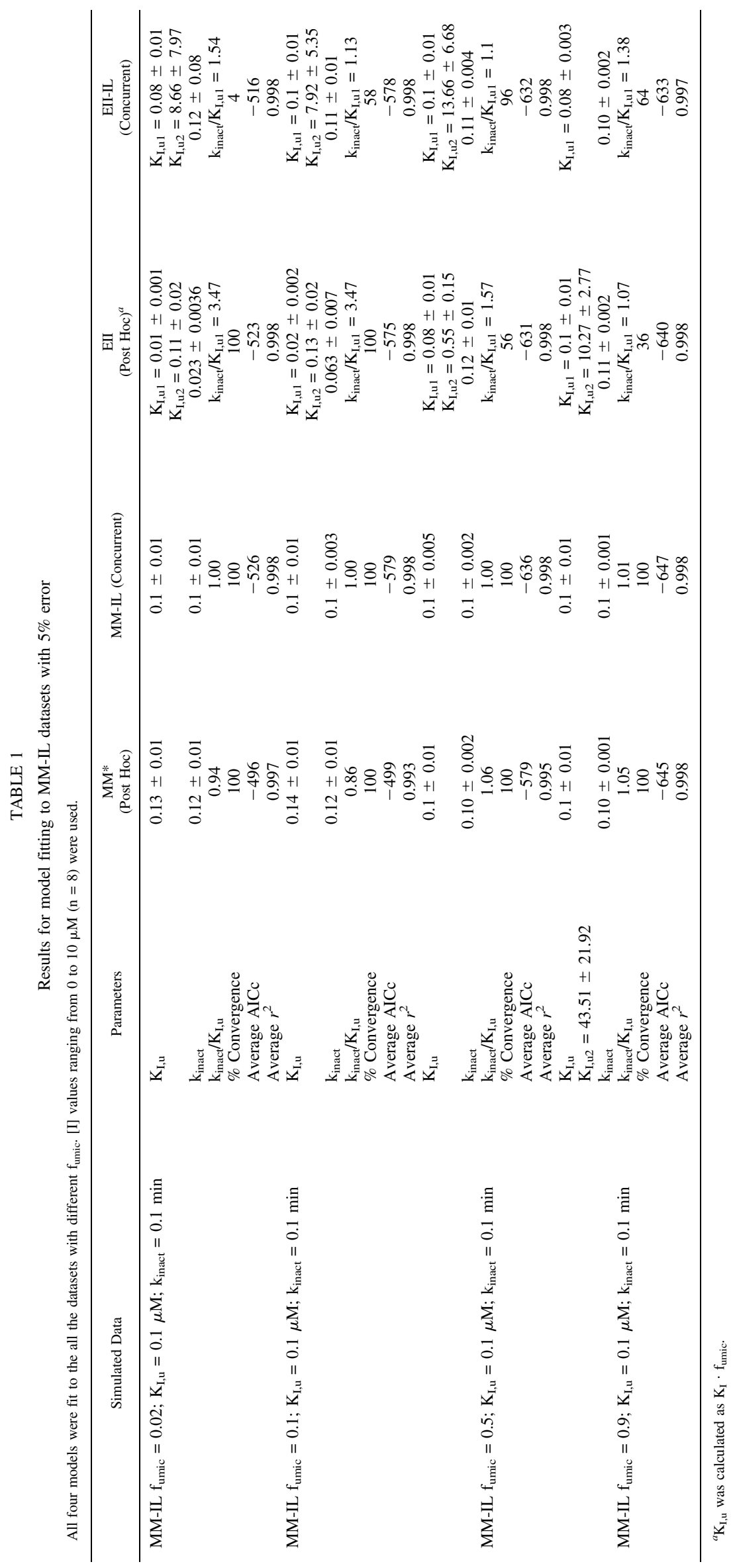


TABLE 2

Results for model fitting to EII-IL datasets with 5\% error

All four models were fit to the all the datasets with different $f_{\text {umic }}$. [I] values $(n=8)$ were used as detailed in the table.

\begin{tabular}{|c|c|c|c|c|c|}
\hline Simulated with & Parameters & MM (Post Hoc) ${ }^{a}$ & MM-IL (Concurrent) & EII (Post Hoc $)^{a}$ & EII-IL (Concurrent) \\
\hline \multirow[t]{6}{*}{$\begin{array}{l}\text { EII-IL } \mathrm{f}_{\mathrm{umic}}=0.02 ; \mathrm{K}_{\mathrm{I}, \mathrm{u} 1}=0.1 \mu \mathrm{M} ; \mathrm{K}_{\mathrm{I}, \mathrm{u} 2}=1 \mu \mathrm{M} ; \mathrm{k}_{\text {inact }}= \\
\quad 0.14 \mathrm{~min} ;[\mathrm{I}] \text { range: } 0-80 \mu \mathrm{M}\end{array}$} & $\mathrm{K}_{\mathrm{I}, \mathrm{u}}$ & DNC & DNC & $\begin{array}{l}\mathrm{K}_{\mathrm{I}, \mathrm{u} 1}=0.004 \pm 0.0002 \\
\mathrm{~K}_{\mathrm{I}, \mathrm{u} 2}=1.66 \pm 0.29\end{array}$ & $\begin{array}{l}\mathrm{K}_{\mathrm{I}, \mathrm{u} 1}=0.08 \pm 0.006 \\
\mathrm{~K}_{\mathrm{I}, \mathrm{u} 2}=0.81 \pm 0.14\end{array}$ \\
\hline & $\mathrm{k}_{\text {inact }}$ & DNC & $\mathrm{DNC}$ & $0.006 \pm 0.001$ & $0.14 \pm 0.032$ \\
\hline & $\mathrm{k}_{\text {inact }} / \mathrm{K}_{\mathrm{I}, \mathrm{u}}$ & DNC & DNC & $\mathrm{k}_{\text {inact }} / \mathrm{K}_{\mathrm{I}, \mathrm{u} 1}=1.53$ & $\mathrm{k}_{\text {inact }} / \mathrm{K}_{\mathrm{I}, \mathrm{u} 1}=1.75$ \\
\hline & $\%$ convergence & 0 & 0 & 64 & 100 \\
\hline & Average AICc & DNC & DNC & -587 & -616 \\
\hline & Average $r^{2}$ & DNC & DNC & 0.997 & 0.998 \\
\hline \multirow[t]{6}{*}{$\begin{array}{l}\text { EII-IL } \mathrm{f}_{\mathrm{umic}}=0.1 ; \mathrm{K}_{\mathrm{I}, \mathrm{u} 1}=0.1 \mu \mathrm{M} ; \mathrm{K}_{\mathrm{I}, \mathrm{u} 2}=1 \mu \mathrm{M} ; \mathrm{k}_{\text {inact }}= \\
\quad 0.14 \mathrm{~min} ;[\mathrm{I}] \text { range: } 0-40 \mu \mathrm{M}\end{array}$} & $\mathrm{K}_{\mathrm{I}, \mathrm{u}}$ & DNC & $13.7 \pm 10.6$ & $\begin{array}{l}\mathrm{K}_{\mathrm{I}, \mathrm{u} 1}=0.008 \pm 0.0004 \\
\mathrm{~K}_{\mathrm{I}, \mathrm{u} 2}=1.21 \pm 0.14\end{array}$ & $\begin{aligned} \mathrm{K}_{\mathrm{I}, \mathrm{u} 1}=0.1 & \pm 0.006 \\
\mathrm{~K}_{\mathrm{I}, \mathrm{u} 2}=0.98 & \pm 0.11\end{aligned}$ \\
\hline & $\mathrm{k}_{\text {inact }}$ & DNC & $2.4 \pm 1.7$ & $0.02 \pm 0.004$ & $0.14 \pm 0.018$ \\
\hline & $\mathrm{k}_{\text {inact }} / \mathrm{K}_{\mathrm{I}, \mathrm{u}}$ & DNC & $0.39 \pm 0.23$ & $\mathrm{k}_{\text {inact }} / \mathrm{K}_{\mathrm{I}, \mathrm{u} 1}=2.88$ & $\mathrm{k}_{\text {inact }} / \mathrm{K}_{\mathrm{I}, \mathrm{u} 1}=1.38$ \\
\hline & $\%$ convergence & 0 & 26 & 76 & 100 \\
\hline & Average AICc & DNC & -398 & -642 & -681 \\
\hline & Average $r^{2}$ & DNC & 0.913 & 0.996 & 0.998 \\
\hline \multirow[t]{6}{*}{$\begin{array}{l}\text { EII-IL } \mathrm{f}_{\mathrm{umic}}=0.5 ; \mathrm{K}_{\mathrm{I}, \mathrm{u} 1}=0.1 \mu \mathrm{M} ; \mathrm{K}_{\mathrm{I}, \mathrm{u} 2}=1 \mu \mathrm{M} ; \mathrm{k}_{\text {inact }}= \\
\quad 0.14 \mathrm{~min} ;[\mathrm{I}] \text { range: } 0-40 \mu \mathrm{M}\end{array}$} & $\mathrm{K}_{\mathrm{I}, \mathrm{u}}$ & $0.02 \pm 0.003$ & $0.04 \pm 0.005$ & $\begin{array}{l}\mathrm{K}_{\mathrm{I}, \mathrm{u} 1}=0.04 \pm 0.002 \\
\mathrm{~K}_{\mathrm{I}, \mathrm{u} 2}=0.94 \pm 0.10\end{array}$ & $\begin{array}{l}\mathrm{K}_{\mathrm{I}, \mathrm{u} 1}=0.1 \pm 0.004 \\
\mathrm{~K}_{\mathrm{I}, \mathrm{u} 2}=1.0 \pm 0.07\end{array}$ \\
\hline & $\mathrm{k}_{\text {inact }}$ & $0.15 \pm 0.01$ & $0.15 \pm 0.01$ & $0.09 \pm 0.01$ & $0.14 \pm 0.01$ \\
\hline & $\mathrm{k}_{\text {inact }} / \mathrm{K}_{\mathrm{I}, \mathrm{u}}$ & $8.2 \pm 1.4$ & $4.2 \pm 0.70$ & $\mathrm{k}_{\text {inact }} / \mathrm{K}_{\mathrm{I}, \mathrm{u} 1}=2.38$ & $\mathrm{k}_{\text {inact }} / \mathrm{K}_{\mathrm{I}, \mathrm{u} 1}=1.40$ \\
\hline & $\%$ convergence & 78 & 100 & 14 & 98 \\
\hline & Average AICc & -529 & -534 & -803 & -808 \\
\hline & Average $r^{2}$ & 0.919 & 0.924 & 0.997 & 0.998 \\
\hline \multirow[t]{6}{*}{$\begin{array}{l}\text { EII-IL } \mathrm{f}_{\mathrm{umic}}=0.9 ; \mathrm{K}_{\mathrm{I}, \mathrm{u} 1}=0.1 \mu \mathrm{M} ; \mathrm{K}_{\mathrm{I}, \mathrm{u} 2}=1 \mu \mathrm{M} ; \mathrm{k}_{\mathrm{inact}}= \\
\quad 0.14 \mathrm{~min} ;[\mathrm{I}] \text { range: } 0-10 \mu \mathrm{M}\end{array}$} & $\mathrm{K}_{\mathrm{I}, \mathrm{u}}$ & $2.0 \pm 0.20$ & $1.98 \pm 0.18$ & $\begin{aligned} \mathrm{K}_{\mathrm{I}, \mathrm{u} 1} & =0.09 \pm 0.01 \\
\mathrm{~K}_{\mathrm{I}, \mathrm{u} 2} & =1.0 \pm 0.08\end{aligned}$ & $\begin{array}{c}\mathrm{K}_{\mathrm{I}, \mathrm{u} 1}=0.1 \pm 0.01 \\
\mathrm{~K}_{\mathrm{I}, \mathrm{u} 22}=1.0 \pm 0.04\end{array}$ \\
\hline & $\mathrm{k}_{\text {inact }}$ & $0.38 \pm 0.02$ & $0.38 \pm 0.02$ & $0.13 \pm 0.01$ & $0.14 \pm 0.01$ \\
\hline & $\mathrm{k}_{\text {inact }} / \mathrm{K}_{\mathrm{I}, \mathrm{u}}$ & $0.2 \pm 0.02$ & $0.2 \pm 0.02$ & $\mathrm{k}_{\text {inact }} / \mathrm{K}_{\mathrm{I}, \mathrm{u} 1}=1.51$ & $\mathrm{k}_{\text {inact }} / \mathrm{K}_{\mathrm{I}, \mathrm{u} 1}=1.40$ \\
\hline & $\%$ convergence & 100 & 100 & 100 & 100 \\
\hline & Average AICc & -557 & -558 & -709 & -709 \\
\hline & Average $r^{2}$ & 0.984 & 0.985 & 0.998 & 0.998 \\
\hline
\end{tabular}

DNC, did not converge.

${ }^{a} \mathrm{~K}_{\mathrm{I}, \mathrm{u}}$ was calculated as $\mathrm{K}_{\mathrm{I}} \cdot \mathrm{f}_{\mathrm{umic}}$.

$\sim 45$-fold higher than with the standard replot method (data not shown).

Next, ITZ in vitro TDI data were modeled. Several models (AICc) were evaluated for ITZ datasets, including MM-IL (-823), MM-IL-M (-899), EII-IL (-859), EII-IL-M (did not converge), MIC-IL (-913), MIC-IL-M (-958), MIC-EII-IL (-939), MIC-EII-M-IL (-972), and MIC-EII-M-Seq-IL (-973). MIC-EII-M-IL and MIC-EII-M-Seq-IL gave comparable fits. The MIC-EII-M-IL model yielded two $\mathrm{K}_{\mathrm{I}, \mathrm{u}}$ estimates for two binding events, $0.024 \pm 0.006$ and $0.037 \pm 0.016 \mu \mathrm{M}$ (Table 4). The net $\mathrm{k}_{\text {inact }}$ value was estimated to be $0.00 \pm 0.004$ minute. MIC-EII-M-IL was able to capture the competitive inhibition (evident from the Y-intercept of Fig. 5) and also the concave upward curvature of the observed data (Fig. 5). The estimated rate constants for the MIC-EII-M-IL model were all well defined (Supplemental Material). However, the propagation of errors to calculate the net $\mathrm{k}_{\text {inact }}$ value resulted in a high error $(0.00 \pm 0.004$ minute) (Table 4). The MIC-EIIM-Seq-IL model and resultant fit are shown in Fig. 6. The observed lag at early preincubation times was captured by this model, but, apparently, metabolite concentrations did not approach saturation.
This " $\mathrm{V}_{\mathrm{max}} / \mathrm{K}_{\mathrm{m}}$ " kinetic range resulted in high covariance between metabolite binding and inactivation. Therefore, results are reported upon fixing the metabolite binding constant (Supplemental Material; Table 4).

\section{Discussion}

The goal of this work was to evaluate the effect of lipid partitioning on TDI kinetics, and to evaluate methods to model lipid partitioning in in vitro TDI assays. Also, this effort aimed to determine the covariance between lipid partitioning and multiple inhibitor binding. Simulations were performed to test how high lipid partitioning could impact the interpretation of TDI kinetics, and experimental TDI datasets were additionally modeled. Finally, the use of in vitro TDI datasets to estimate $\mathrm{f}_{\text {umic }}$ was evaluated.

Lipid partitioning during in vitro assays can be corrected by multiplying total $\mathrm{K}_{\mathrm{I}}$ by $\mathrm{f}_{\mathrm{umic}}$ (post hoc approach) or, with the numerical method, by adding a lipid partitioning component to the model (concurrent approach) (Fig. 1). The advantage of modeling lipid partitioning explicitly is that any

TABLE 3

Results for model fitting of MM-IL and MM models to nondilution MM-IL or EII-IL datasets at $\mathrm{f}_{\mathrm{umic}}=0.02$

\begin{tabular}{|c|c|c|c|}
\hline Simulated with & Parameters & Concurrent & Post $\operatorname{Hoc}^{a}$ \\
\hline \multirow[t]{3}{*}{ MM-IL $\mathrm{f}_{\mathrm{umic}}=0.02 \mathrm{~K}_{\mathrm{I}, \mathrm{u}}=0.1 \mathrm{k}_{\text {inact }}=0.1$} & $\mathrm{~K}_{\mathrm{I}, \mathrm{u}}$ & $0.1 \pm 0.01$ & $0.1 \pm 0.01$ \\
\hline & $\mathrm{k}_{\text {inact }}$ & $0.1 \pm 0.01$ & $0.1 \pm 0.01$ \\
\hline & $\mathrm{k}_{\text {inact }} / \mathrm{K}_{\mathrm{I}, \mathrm{u}}$ & 1.00 & 1.00 \\
\hline \multirow[t]{4}{*}{ EII-IL f $\mathrm{fumic}=0.02 \mathrm{~K}_{\mathrm{I}, \mathrm{u} 1}=0.1 \mathrm{~K}_{\mathrm{I}, \mathrm{u} 2}=1.0 \mathrm{k}_{\text {inact }}=0.14$} & $\mathrm{~K}_{\mathrm{I}, \mathrm{u}}$ & $\mathrm{K}_{\mathrm{I}, \mathrm{u} 1}=0.10 \pm 0.009$ & $\mathrm{~K}_{\mathrm{I}, \mathrm{u} 1}=0.096 \pm 0.009$ \\
\hline & & $\mathrm{K}_{\mathrm{I}, \mathrm{u} 2}=1.00 \pm 0.077$ & $\mathrm{~K}_{\mathrm{I}, \mathrm{u} 2}=1.04 \pm 0.080$ \\
\hline & $\mathrm{k}_{\text {inact }}$ & $0.14 \pm 0.04$ & $0.024 \pm 0.002$ \\
\hline & $\mathrm{k}_{\text {inact }} / \mathrm{K}_{\mathrm{I}, \mathrm{u}}$ & $\mathrm{k}_{\text {inact }} / \mathrm{K}_{\mathrm{I}, \mathrm{u} 1}=1.40$ & $\mathrm{k}_{\text {inact }} / \mathrm{K}_{\mathrm{I}, \mathrm{u} 1}=2.38$ \\
\hline
\end{tabular}

${ }^{a} \mathrm{~K}_{\mathrm{I}, \mathrm{u}}$ calculated as $\mathrm{K}_{\mathrm{I}} \cdot \mathrm{f}_{\mathrm{umic}}$ was parameterized. 
TABLE 4

Comparison of estimates of $\mathrm{K}_{\mathrm{I}, \mathrm{u}}$ and $\mathrm{k}_{\text {inact }}$ by post hoc and concurrent methods

\begin{tabular}{|c|c|c|c|c|c|c|c|c|c|}
\hline \multirow{2}{*}{$\mathrm{f}_{\text {umic }^{a}}{ }^{a}$} & \multirow{2}{*}{ Compound } & \multicolumn{3}{|c|}{ Post Hoc $\left(K_{I} \cdot f_{\text {umic }}\right)$} & \multicolumn{3}{|c|}{ Concurrent } & \multirow{2}{*}{$\begin{array}{l}\mathrm{K}_{\mathrm{I}, \mathrm{u} 1} \text { Fold } \\
\text { Difference }\end{array}$} & \multirow{2}{*}{$\begin{array}{l}\mathrm{k}_{\text {inact }} \text { Fold } \\
\text { Difference }\end{array}$} \\
\hline & & $\mathrm{K}_{\mathrm{I}, \mathrm{u}}$ & $\mathrm{k}_{\text {inact }}$ & $\mathrm{AICc}$ & $\mathrm{K}_{\mathrm{I}, \mathrm{u}}$ & $\mathrm{k}_{\text {inact }}$ & $\mathrm{AICc}$ & & \\
\hline & & $\mu \mathrm{M}$ & $\min$ & & $\mu \mathrm{M}$ & $\min$ & & & \\
\hline 0.24 & PAR & $1.11 \pm 0.21$ & $0.006 \pm 0.002$ & -727 & $0.61 \pm 0.09$ & $0.005 \pm 0.001$ & -762 & 0.56 & 0.83 \\
\hline 0.009 & ITZ model $1^{b}$ & $\begin{array}{c}\mathrm{K}_{\mathrm{I}, \mathrm{u} 1}=0.0008 \pm 0.0001 \\
\mathrm{~K}_{\mathrm{I}}=0.03 \pm 0.009\end{array}$ & $0.005 \pm 0.003$ & -951 & $\begin{array}{l}\mathrm{K}_{\mathrm{I}, \mathrm{ul} 1}=0.024 \pm 0.006 \\
\mathrm{~K}_{\mathrm{U}, \mathrm{U}}=0.037 \pm 0.016\end{array}$ & $0.0042 \pm 0.004$ & -972 & 31.44 & 0.84 \\
\hline 0.009 & ITZ model $2^{b}$ & DNC & $\mathrm{DNC}$ & NA & $\begin{array}{l}\mathrm{K}_{\mathrm{I}, \mathrm{u} 1}=0.015 \pm 0.0005 \\
\mathrm{~K}_{\mathrm{I}, \mathrm{u} 2}=0.062 \text { (fixed) }\end{array}$ & $\mathrm{NA}^{c}$ & -973 & NA & NA \\
\hline
\end{tabular}

DNC, did not converge; NA, not applicable.

${ }^{a} \mathrm{f}_{\text {umic }}$ at $1 \mathrm{mg} / \mathrm{ml}$.

${ }^{b} \mathrm{~K}_{\mathrm{I}, \mathrm{u} 1}$ used for calculation of $\mathrm{k}_{\mathrm{inact}} / \mathrm{K}_{\mathrm{I}, \mathrm{u}}$.

cThe metabolite did not reach saturation ("V/K" range).

shift in the equilibrium is captured, as evident from Fig. 1. Moreover, since the estimates for $\mathrm{k}_{\text {on }}$ and $\mathrm{k}_{\mathrm{off}}$ (eq. 1) obtained from the measurement of $\mathrm{f}_{\mathrm{umic}}$ can be fixed during the modeling process, it does not impact the number of TDI parameters to be estimated.

P450 enzymes are known for exhibiting atypical kinetics (Korzekwa et al., 1998; Hutzler and Tracy, 2002; Atkins, 2005; Tracy, 2006; Denisov and Sligar, 2012). Our previous studies have discussed how atypical kinetics influence TDI kinetics (Korzekwa et al., 2014; Nagar et al., 2014; Barnaba et al., 2016; Yadav et al., 2018) and impact DDI predictions (Yadav et al., 2018). Atypical kinetics in TDI can result from multiple binding events (Fisher et al., 1970; Korzekwa et al., 1998), nonequilibrating enzyme populations (Pearson et al., 2006; Davydov and Halpert, 2008), functional heterogeneity (Rodgers et al., 2018), oligomerization of different P450 enzymes (Denisov et al., 2009; Davydov et al., 2013, 2015, 2017), saturable or nonsaturable inactivator depletion during preincubation (Yadav et al., 2018), or a combination of these processes. These processes can be further complicated by partitioning of the substrate or inhibitor into microsomal membranes in vitro.

In some cases, lipid partitioning may be misinterpreted as a doublebinding event, leading to incorrect parameter estimates. For example, in Table 1 (MM-IL datasets), when $\mathrm{f}_{\text {umic }}=0.02$, the MM-IL and EII model fits were indistinguishable $(\delta \mathrm{AICc}=3)$. This can result in incorrect model selection and can further lead to errors in TDI-mediated DDI predictions. For less partitioned datasets ( $f_{\text {umic }}$ values of 0.1 and 0.5 ), the inclusion of partitioning resulted in better models. These simulations are consistent with the experimental results for PAR ( $f_{\text {umic }}=0.24$, MIC-M-IL is the best fit model) (Fig. 4). When the $f_{\text {umic }}$ value approaches 1 , MM-IL collapses into MM, and both models provide equally good fits to the MM-IL dataset.

When EII-IL datasets were modeled (Table 2), the correct (EII-IL) model was always the statistically best fit model from $\mathrm{f}_{\mathrm{umic}}$ values of $0.02-0.5$. These simulations are consistent with experimental results for ITZ $\left(f_{\text {umic }}=0.009\right.$; the two best fit models were EII-IL type models) (Figs. 5 and 6). Again, as expected, at $\mathrm{f}_{\text {umic }}=0.9$, EII-IL collapsed to EII. At high microsomal partitioning, MM models did not always converge. Even with moderate microsomal partitioning, the MM models converged but displayed significantly poorer fits than the EII models. Thus, although multiple binding and lipid partitioning are highly correlated, the two events can be deconvoluted by the use of experimental $f_{\text {umic }}$ data. Together, the data in Tables 1 and 2 clearly suggest the importance of measuring $f_{u m i c}$ and using this value explicitly in models for in vitro TDI kinetics.

The need to include $f_{\text {umic }}$ values in the model (concurrent method) arises whenever the dilution experimental design is used for in vitro TDI assays. Table 3 clearly shows that with a nondilution experimental design, the $K_{\mathrm{i}}$ value can be accurately corrected post hoc with the experimental $f_{u m i c}$ value, even in the presence of complex kinetics. Although the use of dilution has been embraced to avoid competitive inhibition of substrate metabolism (Mohutsky and Hall, 2014), we have previously shown that the numerical method works equally well for dilution and nondilution datasets (Nagar et al., 2014). In either case, experimental measurement of $f_{u m i c}$ is necessary to accurately model and interpret TDI datasets.

The best kinetic parameters for PAR and ITZ are consistent with their reported mechanism and kinetics. PAR, which is known to inactivate P450 enzymes by the formation of carbene intermediate, was observed to be a typical MIC-forming inactivator showing concave upward curvature in the PRA plot (Fig. 4B). Both the MIC-M-IL and MIC-EII-M models were tested, and MIC-M-IL was the better model. Moreover, CYP2D6 is not known to show doublebinding kinetics (McMasters et al., 2007). It is interesting that the estimated $\mathrm{k}_{\text {inact }}$ value is small (0.005 minute) for PAR (Table 4). PAR is a methylenedioxyphenyl compound that is converted to an $\mathrm{Fe}^{+3}$-carbene intermediate and further reduced to an $\mathrm{Fe}^{+2}$-carbene intermediate. For a similar compound, MDMA (3,4-methylenedioxymethamphetamine), both $\mathrm{Fe}^{+3}$ and $\mathrm{Fe}^{+2}$ intermediates were shown to inhibit CYP2D6 activity in a slowly reversible manner (Rodgers et al., 2018). This mechanism, combined with the long in vivo halflife of PAR (an average of 21 hours in humans, with 2 weeks needed to achieve steady state) (Sanchez et al., 2014), may be responsible for the observed DDIs. This can be addressed only by dynamic in vitro-in vivo modeling and will not be captured with static DDI prediction methods (i.e., directly with $\mathrm{k}_{\text {inact }}$ values).

ITZ is a potent inhibitor and a type II binder of P450 enzymes (von Moltke et al., 1996; Wang et al., 1999; Galetin et al., 2005; Isin and Guengerich, 2007; Foti et al., 2010). The PRA plot showed that ITZ is a strong competitive inhibitor and an inactivator (Fig. 5). Non-MMs were also evident from the PRA plot. Two models provided similar fits, and a "best fit" model was not identifiable. One model included a combination of multiple binding, lipid partitioning, and inhibitor depletion. The second model additionally included Seq metabolism and inactivation by the metabolite. ITZ shows multiple binding kinetics (Pearson et al., 2006; Locuson et al., 2007), high partitioning (Ishigam et al., 2001; Galetin et al., 2005), and extensive metabolism (Templeton et al., 2008; Rougee et al., 2017). ITZ metabolites are also reported to be CYP3A inhibitors (Isoherranen et al., 2004; Templeton et al., 2010). An observed lag in inactivation was fit better with an MIC-EII-M-Seq-IL model (Fig. 6). However, the lack of metabolite data limits our ability to completely parameterize and interpret this model. Presumably, lack of saturating metabolite concentrations led to complete covariance between metabolite binding and inactivation. Therefore, neither $\mathrm{K}_{\mathrm{I}}$ nor $\mathrm{k}_{\text {inact }}$ values could be estimated. Only $\mathrm{k}_{\text {inact }} / \mathrm{K}_{\mathrm{I}}$ could be calculated, using the method 
of net rate constants (Cleland, 1975). Interestingly, for both ITZ models in Table $4, \mathrm{k}_{\text {inact }} / \mathrm{K}_{\mathrm{I}}$ values were similar ( 0.17 with ITZ model 1 vs. 0.12 with ITZ model 2). Irrespective of the model used, the low estimate of $\mathrm{k}_{\text {inact }}$ supports previous reports that the DDI potential of ITZ is due to competitive inhibition by the parent as well as metabolites (Isoherranen et al., 2004; Templeton et al., 2008).

It should be noted that models for PAR and ITZ were developed with certain assumptions. These assumptions include MIC formation, inhibitor loss due to metabolism, Seq metabolism, and lipid partitioning, and are based on mechanisms proposed in the literature. For example, ITZ is known to undergo Seq metabolism, and the low inhibitor concentrations used in in vitro studies suggest that inhibitor loss must be considered. Although the models compared in this study are based on expected kinetic characteristics, additional details (e.g., ITZ metabolite kinetics) may result in different models or improved model identifiability. As seen for the two ITZ models (Figs. 5 and 6), model identifiability is limited by current mechanistic paradigms and available data.

Finally, results in Table 4 clearly show that the concurrent inclusion of the $f_{\text {umic }}$ in the models provides better fits compared with a post hoc correction with $\mathrm{f}_{\text {umic }}$. This is due to a shift in the equilibrium upon a dilution assay, which can cause differences in inactivator concentrations in secondary incubation (Fig. 2), leading to differences in estimation of $\mathrm{K}_{\mathrm{I}, \mathrm{u}}$ and $\mathrm{k}_{\text {inact }}$ values. As with the simulations, the experimental data and modeling underline the importance of collecting experimental $f_{\text {umic }}$ values and incorporating these values into models for TDI kinetics.

\section{Conclusions}

It is clear that the standard replot method can only be used for simple kinetic systems with low experimental errors. The numerical method easily allows the incorporation of observed kinetic complexities, but inactivator partitioning must be modeled explicitly for dilution assays. For some TDI kinetic models, lipid partitioning can be covariant with multiple inhibitor binding to the enzyme. For most kinetic schemes, including lipid partitioning in the models results in better fits, as judged by AICc values, parameter errors, correlation matrices, and weighted residual plots. Models with lipid partitioning can have markedly different estimates of $\mathrm{K}_{\mathrm{I}, \mathrm{u}}$ and $\mathrm{k}_{\text {inact }}$, leading to potentially different predictions of drug interactions. For datasets with a dilution experimental design, the concurrent inclusion of lipid partitioning in models is better than a post hoc correction with $\mathrm{f}_{\text {umic }}$. An alternate experimental design is to conduct nondilution TDI assays and to incorporate $f_{u m i c}$ in a post hoc manner. Although $f_{u m i c}$ values can be accurately estimated from some TDI datasets, many of the more complex models will not converge. In conclusion, observed kinetic complexities should be modeled with numerical methods, and lipid partitioning (i.e., experimental $\mathrm{f}_{\mathrm{umic}}$ values) should be explicitly incorporated into the models when dilution protocols are used.

\section{Authorship Contributions}

Participated in research design: Yadav, Korzekwa, and Nagar.

Conducted experiments: Yadav.

Performed data analysis: Yadav, Korzekwa, and Nagar.

Wrote or contributed to the writing of the manuscript: Yadav, Korzekwa, and Nagar.

\section{References}

Akaike H (1974) A new look at the statistical model identification. IEEE Trans Automat Contr 19:716-723

Atkins WM (2005) Non-Michaelis-Menten kinetics in cytochrome P450-catalyzed reactions. Annu Rev Pharmacol Toxicol 45:291-310.

Austin RP, Barton P, Cockroft SL, Wenlock MC, and Riley RJ (2002) The influence of nonspecific microsomal binding on apparent intrinsic clearance, and its prediction from physicochemical properties. Drug Metab Dispos 30:1497-1503.
Barnaba C, Yadav J, Nagar S, Korzekwa K, and Jones JP (2016) Mechanism-based inhibition of CYP3A4 by podophyllotoxin: aging of an intermediate is important for in vitro/in vivo correlations. Mol Pharm 13:2833-2843.

Cleland WW (1975) Partition analysis and the concept of net rate constants as tools in enzyme kinetics. Biochemistry 14:3220-3224.

Cohen SD, Pumford NR, Khairallah EA, Boekelheide K, Pohl LR, Amouzadeh HR, and Hinson JA (1997) Selective protein covalent binding and target organ toxicity. Toxicol Appl Pharmacol 143:1-12.

Davydov DR, Davydova NY, Rodgers JT, Rushmore TH, and Jones JP (2017) Toward a systems approach to the human cytochrome P450 ensemble: interactions between CYP2D6 and CYP2E1 and their functional consequences. Biochem J 474:3523-3542.

Davydov DR, Davydova NY, Sineva EV, and Halpert JR (2015) Interactions among cytochromes P450 in microsomal membranes: oligomerization of cytochromes P450 3A4, 3A5, and 2E1 and its functional consequences. J Biol Chem 290:3850-3864.

Davydov DR, Davydova NY, Sineva EV, Kufareva I, and Halpert JR (2013) Pivotal role of P450-P450 interactions in CYP3A4 allostery: the case of $\alpha$-naphthoflavone. Biochem J 453:219-230.

Davydov DR and Halpert JR (2008) Allosteric P450 mechanisms: multiple binding sites, multiple conformers or both? Expert Opin Drug Metab Toxicol 4:1523-1535.

Denisov IG, Frank DJ, and Sligar SG (2009) Cooperative properties of cytochromes P450. Pharmacol Ther 124:151-167.

Denisov IG and Sligar SG (2012) A novel type of allosteric regulation: functional cooperativity in monomeric proteins. Arch Biochem Biophys 519:91-102.

Fersht A (2017) Structure and Mechanism in Protein Science: A Guide to Enzyme Catalysis and Protein Folding, World Scientific, Hackensack, NJ.

Fisher HF, Gates RE, and Cross DG (1970) A ligand exclusion theory of allosteric effects. Nature 228:247-249.

Foti RS, Rock DA, Wienkers LC, and Wahlstrom JL (2010) Selection of alternative CYP3A4 probe substrates for clinical drug interaction studies using in vitro data and in vivo simulation. Drug Metab Dispos 38:981-987.

Galetin A, Burt H, Gibbons L, and Houston JB (2006) Prediction of time-dependent CYP3A4 drug-drug interactions: impact of enzyme degradation, parallel elimination pathways, and intestinal inhibition. Drug Metab Dispos 34:166-175.

Galetin A, Ito K, Hallifax D, and Houston JB (2005) CYP3A4 substrate selection and substitution in the prediction of potential drug-drug interactions. J Pharmacol Exp Ther 314:180-190.

Grimm SW, Einolf HJ, Hall SD, He K, Lim H-K, Ling K-HJ, Lu C, Nomeir AA, Seibert E, Skordos KW, et al. (2009) The conduct of in vitro studies to address time-dependent inhibition of drug-metabolizing enzymes: a perspective of the pharmaceutical research and manufacturers of America. Drug Metab Dispos 37:1355-1370.

Hutzler JM and Tracy TS (2002) Atypical kinetic profiles in drug metabolism reactions. Drug Metab Dispos 30:355-362.

Ishigam M, Uchiyama M, Kondo T, Iwabuchi H, Inoue S, Takasaki W, Ikeda T, Komai T, Ito K, and Sugiyama Y (2001) Inhibition of in vitro metabolism of simvastatin by itraconazole in humans and prediction of in vivo drug-drug interactions. Pharm Res 18:622-631.

Isin EM and Guengerich FP (2007) Multiple sequential steps involved in the binding of inhibitors to cytochrome P450 3A4. J Biol Chem 282:6863-6874.

Isoherranen N, Kunze KL, Allen KE, Nelson WL, and Thummel KE (2004) Role of itraconazole metabolites in CYP3A4 inhibition. Drug Metab Dispos 32:1121-1131.

Kalvass JC, Tess DA, Giragossian C, Linhares MC, and Maurer TS (2001) Influence of microsomal concentration on apparent intrinsic clearance: implications for scaling in vitro data. Drug Metab Dispos 29:1332-1336.

Korzekwa K, Tweedie D, Argikar UA, Whitcher-Johnstone A, Bell L, Bickford S, and Nagar S (2014) A numerical method for analysis of in vitro time-dependent inhibition data. Part 2. Application to experimental data. Drug Metab Dispos 42:1587-1595.

Korzekwa KR, Krishnamachary N, Shou M, Ogai A, Parise RA, Rettie AE, Gonzalez FJ, and Tracy TS (1998) Evaluation of atypical cytochrome P450 kinetics with two-substrate models: evidence that multiple substrates can simultaneously bind to cytochrome P450 active sites. Biochemistry 37:4137-4147.

Locuson CW, Hutzler JM, and Tracy TS (2007) Visible spectra of type II cytochrome P450-drug complexes: evidence that "incomplete" heme coordination is common. Drug Metab Dispos 35:614-622.

Mao J, Mohutsky MA, Harrelson JP, Wrighton SA, and Hall SD (2011) Prediction of CYP3Amediated drug-drug interactions using human hepatocytes suspended in human plasma. Drug Metab Dispos 39:591-602.

Margolis JM and Obach RS (2003) Impact of nonspecific binding to microsomes and phospholipid on the inhibition of cytochrome P4502D6: implications for relating in vitro inhibition data to in vivo drug interactions. Drug Metab Dispos 31:606-611.

McLure JA, Miners JO, and Birkett DJ (2000) Nonspecific binding of drugs to human liver microsomes. Br J Clin Pharmacol 49:453-461.

McMasters DR, Torres RA, Crathern SJ, Dooney DL, Nachbar RB, Sheridan RP, and Korzekwa KR (2007) Inhibition of recombinant cytochrome P450 isoforms 2D6 and 2C9 by diverse druglike molecules. J Med Chem 50:3205-3213.

Mohutsky M and Hall SD (2014) Irreversible enzyme inhibition kinetics and drug-drug interactions, in Enzyme Kinetics in Drug Metabolism, pp 57-91, Humana Press, New York City, NY.

Mullins ME, Horowitz BZ, Linden DH, Smith GW, Norton RL, and Stump J (1998) Lifethreatening interaction of mibefradil and $\beta$-blockers with dihydropyridine calcium channel blockers. JAMA 280:157-158.

Nagar S, Jones JP, and Korzekwa K (2014) A numerical method for analysis of in vitro timedependent inhibition data. Part 1. Theoretical considerations. Drug Metab Dispos 42:1575-1586.

Nagar S and Korzekwa K (2012) Commentary: nonspecific protein binding versus membrane partitioning: it is not just semantics. Drug Metab Dispos 40:1649-1652.

Obach RS (1997) Nonspecific binding to microsomes: impact on scale-up of in vitro intrinsic clearance to hepatic clearance as assessed through examination of warfarin, imipramine, and propranolol. Drug Metab Dispos 25:1359-1369.

Obach RS (1999) Prediction of human clearance of twenty-nine drugs from hepatic microsomal intrinsic clearance data: an examination of in vitro half-life approach and nonspecific binding to microsomes. Drug Metab Dispos 27:1350-1359.

Obach RS, Walsky RL, Venkatakrishnan K, Gaman EA, Houston JB, and Tremaine LM (2006) The utility of in vitro cytochrome $\mathrm{P} 450$ inhibition data in the prediction of drug-drug interactions. J Pharmacol Exp Ther 316:336-348. 
Parkinson A, Kazmi F, Buckley DB, Yerino P, Paris BL, Holsapple J, Toren P, Otradovec SM, and Ogilvie BW (2011) An evaluation of the dilution method for identifying metabolismdependent inhibitors of cytochrome P450 enzymes. Drug Metab Dispos 39:1370-1387.

Pearson JT, Hill JJ, Swank J, Isoherranen N, Kunze KL, and Atkins WM (2006) Surface plasmon resonance analysis of antifungal azoles binding to CYP3A4 with kinetic resolution of multiple binding orientations. Biochemistry 45:6341-6353.

Pham C, Nagar S, and Korzekwa K (2017) Numerical analysis of time dependent inhibition kinetics: comparison between rat liver microsomes and rat hepatocyte data for mechanistic model fitting. Xenobiotica $1-28$.

Rodgers JT, Davydova NY, Paragas EM, Jones JP, and Davydov DR (2018) Kinetic mechanism of time-dependent inhibition of CYP2D6 by 3,4-methylenedioxymethamphetamine (MDMA): functional heterogeneity of the enzyme and the reversibility of its inactivation. Biochem Pharmacol 156:86-98.

Rougée LRA, Mohutsky MA, Bedwell DW, Ruterbories KJ, and Hall SD (2017) The impact of the hepatocyte-to-plasma $\mathrm{pH}$ gradient on the prediction of hepatic clearance and drug-drug interactions for CYP2C9 and CYP3A4 substrates. Drug Metab Dispos 45:1008-1018.

Rowland Yeo K, Walsky RL, Jamei M, Rostami-Hodjegan A, and Tucker GT (2011) Prediction of time-dependent CYP3A4 drug-drug interactions by physiologically based pharmacokinetic modelling: impact of inactivation parameters and enzyme turnover. Eur J Pharm Sci 43:160-173.

Sanchez C, Reines EH, and Montgomery SA (2014) A comparative review of escitalopram, paroxetine, and sertraline: are they all alike? Int Clin Psychopharmacol 29:185-196.

Stresser DM, Mao J, Kenny JR, Jones BC, and Grime K (2014) Exploring concepts of in vitro timedependent CYP inhibition assays. Expert Opin Drug Metab Toxicol 10:157-174.

Templeton I, Peng CC, Thummel KE, Davis C, Kunze KL, and Isoherranen N (2010) Accurate prediction of dose-dependent CYP3A4 inhibition by itraconazole and its metabolites from in vitro inhibition data. Clin Pharmacol Ther 88:499-505.

Templeton IE, Thummel KE, Kharasch ED, Kunze KL, Hoffer C, Nelson WL, and Isoherranen N (2008) Contribution of itraconazole metabolites to inhibition of CYP3A4 in vivo. Clin Pharmacol Ther 83:77-85.
Tracy TS (2006) Atypical cytochrome p450 kinetics: implications for drug discovery. Drugs $R$ D 7: 349-363.

Venkatakrishnan K and Obach RS (2007) Drug-drug interactions via mechanism-based cytochrome P450 inactivation: points to consider for risk assessment from in vitro data and clinical pharmacologic evaluation. Curr Drug Metab 8:449-462.

von Moltke LL, Greenblatt DJ, Schmider J, Duan SX, Wright CE, Harmatz JS, and Shader R (1996) Midazolam hydroxylation by human liver microsomes in vitro: inhibition by fluoxetine, norfluoxetine, and by azole antifungal agents. J Clin Pharmacol 36:783-791.

Wang JS, Wen X, Backman JT, Taavitsainen P, Neuvonen PJ, and Kivistö KT (1999) Midazolam $\alpha$-hydroxylation by human liver microsomes in vitro: inhibition by calcium channel blockers, itraconazole and ketoconazole. Pharmacol Toxicol 85:157-161.

Watanabe A, Nakamura K, Okudaira N, Okazaki O, and Sudo K (2007) Risk assessment for drug drug interaction caused by metabolism-based inhibition of CYP3A using automated in vitro assay systems and its application in the early drug discovery process. Drug Metab Dispos 35 $1232-1238$.

Waters NJ, Obach RS, and Di L (2014) Consideration of the unbound drug concentration in enzyme kinetics, in Enzyme Kinetics in Drug Metabolism, pp 119-145, Humana Press, New York City, NY

Yadav J, Korzekwa K, and Nagar S (2018) Improved predictions of drug-drug interactions mediated by time-dependent inhibition of CYP3A. Mol Pharm 15:1979-1995.

Zhou S-F, Xue CC, Yu X-Q, Li C, and Wang G (2007) Clinically important drug interactions potentially involving mechanism-based inhibition of cytochrome P450 3A4 and the role of therapeutic drug monitoring. Ther Drug Monit 29:687-710.

Address correspondence to: Dr. Swati Nagar, Department of Pharmaceutical Sciences, Temple University School of Pharmacy, 3307 N Broad Street, Philadelphia, PA 19140. E-mail: snagar@temple.edu 